\title{
TUJUH KONTAK KONSELING MENYUSUI SEBAGAI UPAYA MENCEGAH TERJADINYA POSTPARTUM BLUES
}

\author{
Yanik Muyassaroh $^{1)}$; Aulia Fatmayanti' ${ }^{2}$; Anjar Astuti' ${ }^{3)}$ Kuswanto $^{4)}$ \\ Poltekkes Kemenkes Semarang \\ yanikmuyass@gmail.com
}

\begin{abstract}
Postpartum blues is the onset of mental disorders in mothers postpartum, which in turn can adversely affect the mother and the baby. One of the factors triggering postpartum the difficulty breastfeeding which can increase the risk of depression. 7 contacts lactation counseling done from the beginning that since the mother's womb 28 weeks old after birth is not expected to happen later breastfeeding difficulties that can lead to postpartum blues. This has encouraged the devotees to carry out the Community Service (Pengabmas) dissemination of research results in the form of seven contacts influence on the incidence of postpartum lactation counseling blues at the Village Karangjati City District Blora Blora.

Service to the community is intended to provide education to pregnant women in order to prepare for the postpartum period to be able to provide exclusive breastfeeding to reduce the risk of postpartum blues. Community service activities are carried out at 7 meetings in PKD Karangjati using methods lectures, discussion, and demonstration. This activity begins with the pre-test and post-test ends with the result is increased knowledge after being given counseling with a lecture and demonstration.

The conclusion form the community service is an increased knowledge of pregnant women about the benefits of seven contacts lactation counseling can reduce the risk of postpartum blues.
\end{abstract}

Keywords: Seven contacts counseling, breastfeeding, postpartum blues

\begin{abstract}
ABSTRAK
Postpartum blues merupakan awal terjadinya gangguan mental pada ibu postpartum, yang nantinya bisa berdampak buruk pada ibu dan bayinya. Salah satu faktor pemicu postpartum blues yaitu kesulitan menyusui yang dapat meningkatkan risiko depresi. Dilakukannya 7 kontak konseling laktasi sejak awal yaitu sejak kandungan ibu berusia 28 minggu diharapkan nanti setelah melahirkan tidak terjadi kesulitan untuk menyusui yang bisa memicu terjadinya postpartum blues. Hal inilah yang mendorong pengabdi untuk melaksanakan kegiatan Pengabdian kepada Masyarakat (Pengabmas) berupa diseminasi hasil penelitian pengaruh tujuh kontak konseling laktasi terhadap kejadian postpartum blues di Desa Karangjati Kecamatan Kota Blora Kabupaten Blora.

Pengabdian kepada masyarakat ini bertujuan untuk memberikan edukasi kepada ibu hamil untuk bisa mempersiapkan diri menghadapi masa postpartum untuk bisa memberikan asi eksklusif sehingga mengurangi risiko terjadinya postpartum blues. Kegiatan pengabdian masyarakat ini dilaksanakan sebanyak 7 kali pertemuan di PKD
\end{abstract}


Kelurahan Karangjati dengan menggunakan metode ceramah, tanya jawab dan demonstrasi. Kegiatan ini diawali dengan pre test dan diakhiri dengan post test dengan hasil terjadi peningkatan pengetahuan setelah diberikan penyuluhan dengan metode ceramah dan demonstrasi.

Kesimpulan dari pengabdian masyarakat ini yaitu ada peningkatan pengetahuan ibu hamil tentang manfaat tujuh kontak konseling laktasi yang diharapkan bisa membantu mengurangi risiko terjadinya postpartum blues.

Kata Kunci: Tujuh kontak konseling, ASI, postpartum blues

\section{PENDAHULUAN}

Postpartum blues merupakan awal terjadinya gangguan mental pada ibu postpartum, yang nantinya bisa berdampak buruk pada ibu dan bayinya. Postpartum blues atau sering juga disebut sebagai maternity blues adalah suatu sindrom gangguan mental ringan yang sering tampak dalam seminggu pertama setelah persalinan dan ditandai dengan gejala-gejala seperti reaksi depresi, sedih, disforia, menangis, mudah tersinggung (iritabilitas), cemas, labilitas perasaan, gangguan tidur dan gangguan nafsu makan (Marshall, 2004).

Angka kejadian postpartum blues cukup tinggi yakni 26\% - 85\%. Dari beberapa penelitian dijelaskan sebanyak 50\% ibu setelah melahirkan mengalami depresi setelah melahirkan dan hampir $80 \%$ ibu baru atau primipara mengalami perasaan sedih setelah melahirkan. Sedangkan di Indonesia angka kejadian postpartum blues berkisar 50\%- 70 $\%$, dan hal ini dapat berlanjut menjadi depresi postpartum dengan jumlah bervariasi dari $5 \%$ hingga lebih dari 25\% (Bobak, et al 2005).

Penyebab postpartum blues masih belum bisa diketahui secara pasti. Namun, ada beberapa faktor yang diperkirakan memicu terjadinya postpartumblues. Beck (2006), melalui studi meta analisisnya memaparkan beberapa variable prediktor yang dapat menimbulkan postpartum blues. Prediktor tersebut antara lain depresi pranatal, stres merawat anak (childcare stress), stress kehidupan sehari-hari (stressful life event), dukungan sosial, kecemasan pranatal, keintiman suami istri, riwayat depresi sebelumnya, self esteem, temperamen bayi, single marital status, status sosial ekonomi dan kehamilan yang tidak diinginkan atau tidak terencana.

Menurut Amir, et al (1996) dalam Tacked et al (2007), salah satu faktor yang menyebabkan postpartum blues yaitu kesulitan menyusui, yang dapat meningkatkan risiko depresi. Kesulitan-kesulitan ini termasuk puting nyeri, kelelahan, dan ibu-ibu yang mengkhawatirkan menyusui. 
Dalam penelitian yang lain, setelah masalah menyusui teratasi, ibu tidak lagi tertekan atau mengalami depresi. Hampir semua studi mengaitkan durasi menyusui dengan depresi postpartum. Postpartum depression memprediksi dan diprediksi oleh penghentian proses menyusui dalam beberapa penelitian. Durasi menyusui yang lebih pendek bisa meningkatkan gejala depresi selama postpartum (Dias dan Figueiredo, 2015).

Menurut Groer, et al (2002), menyusui bisa melindungi kesehatan mental ibu, mengurangi stres dan menimbulkan ketenangan. Para peneliti juga menemukan bahwa menyusui bisa menurunkan mood negatif (Mezzacappa dan Katkin, 2002). Menyusui juga menganugerahkan banyak manfaat kesehatan untuk ibu dan bayi, sementara depresi akan memberikan pengaruh negatif bagi ibu dan bayi (Bogen et al, 2010). Menurut penelitian yang dilakukan oleh (Zubaran dan Foresti, 2013), menunjukkan bahwa ibu yang menderita gejala depresi mungkin mengalami kurang percaya diri dalam kemampuan mereka untuk menyusui. Dilakukannya 7 kontak konseling laktasi sejak awal yaitu sejak kandungan ibu berusia 28 minggu diharapkan nanti setelah melahirkan tidak terjadi kesulitan untuk menyusui yang bisa memicu terjadinya postpartum blues.

Hal ini mendorong Prodi DIII Kebidanan Blora Poltekkes Kemenkes Semarang yang memiliki visi utama di bidang keahlian laktasi, untuk melaksanakan kegiatan Pengabdian kepada Masyarakat (Pengabmas) berupa diseminasi hasil penelitian pengaruh tujuh kontak konseling laktasi terhadap kejadian postpartum blues di Desa Karangjati Kecamatan Kota Blora Kabupaten Blora, sebagai bentuk dukungan terhadap program pemerintah di bidang kesehatan dan perwujudan Tri Dharma Perguruan Tinggi.

\section{METODE PELAKSANAAN}

Sasaran dalam kegiatan pengabdian masyarakat Prodi DIII Kebidanan Blora Poltekkes Kemenkes Semarang ini adalah 45 ibu hamil TM I, II, maupun III di Poliklinik Kesehatan Desa Kelurahan Karangjati.

Kegiatan pengabmas ini dilaksanakan sebanyak 7x pertemuan di PKD Kelurahan Karangjati setiap hari Sabtu mulai tgl 15 Juli sampai tgl 26 Agustus, dengan rincian sebagai berikut : 
Pertemuan I : Pre test dan pemberian materi tentang anatomi payudara dan fisiologi menyusui (mekanisme produksi ASI dan cara kerja menyusui), keuntungan menyusui, manfaat ASI, dampak dan bahaya susu formula-dot, risiko tidak memberikan ASI - tidak menyusui dan perawatan payudara selama hamil.

Pertemuan II : Diulang pembahasan di pertemuan 1 dan lebih menekankan mengenai seputar IMD serta diberikan informasi mengenai fisiologi pembentukan ASI (laktogenesis 2).

Pertemuan III : Pentingnya rawat gabung dan bedding in.

Pertemuan IV : Demonstrasi cara memosisikan bayi dan membantu bayi menyusui dengan perlekatan yang baik, diberikan informasi mengenai perkembangan berat badan bayi ASI eksklusif, keuntungan rawat gabung dan skin to skin contact.

Pertemuan V : Gizi ibu menyusui dan tentang pembentukan ASI tahap 2 (laktogenesis 2).

Pertemuan VI : Masalah atau kendala yang timbul pada proses menyusui.

Pertemuan VII : Manajemen ASI Perah untuk persiapan ibu bekerja (demonstrasi cara memerah ASI), post test.

Intervensi yang dilakukan dengan metode ceramah dan demonstrasi. Evaluasi dalam kegiatan ini yaitu pre test sebelum penyuluhan, dan post test setelah penyuluhan dengan ibu hamil peserta kegiatan pengabdian kepada masyarakat "Tujuh Kontak Konseling Menyusui sebagai Upaya Mencegah Terjadinya Postpartum blues".

\section{HASIL DAN PEMBAHASAN}

Kegiatan pengabdian masyarakat penyuluhan Tujuh Kontak Konseling Laktasi ini dilaksanakan di Poliklinik Kesehatan Desa Kelurahan Karangjati dihadiri oleh 45 orang ibu hamil baik TM I, II, maupun III.

Berikut adalah karakteristik peserta kegiatan pengabdian masyarakat: 
Tabel 1. Karakteristik Peserta Kegiatan Pengabmas Berdasarkan Tingkat Pendidikan

\begin{tabular}{crc}
\hline Tingkat Pendidikan & F & \% \\
\hline SD & 7 & 15,5 \\
SMP & 12 & 26,7 \\
SMA & 21 & 46,7 \\
Diploma/Sarjana & 5 & 11,1 \\
\hline Total & 45 & 100
\end{tabular}

Sumber: Data Primer, 2017

Berdasarkan tabel 1 dapat diketahui bahwa sebagian besar responden berpendidikan SMA yaitu sebesar $46,7 \%$.

Tabel 2. Karakteristik Peserta Kegiatan Pengabmas Berdasarkan Pekerjaan

\begin{tabular}{ccc}
\hline Pekerjaan & F & \% \\
\hline IRT & 25 & 55,6 \\
Swasta & 15 & 33,3 \\
PNS & 5 & 11,1 \\
\hline Total & 45 & 100 \\
\hline
\end{tabular}

Sumber: Data Primer, 2017

Berdasarkan tabel 2 dapat diketahui bahwa sebagian besar responden bekerja sebagai IRT (Ibu Rumah Tangga) yaitu sebesar 55,6\%.

Tabel 3. Karakteristik Peserta Kegiatan Pengabmas Berdasarkan Paritas

\begin{tabular}{ccc}
\hline Paritas & F & \% \\
\hline Primigravida & 15 & 33,3 \\
Multigravida & 30 & 66,7 \\
\hline Total & 45 & 100
\end{tabular}

Sumber: Data Primer, 2017

Berdasarkan tabel 3 dapat diketahui bahwa sebagian besar responden adalah ibu multigravida yaitu sebesar $66,7 \%$.

Tabel 4. Perbedaan Pengetahuan Peserta Kegiatan Pengabmas Sebelum dan Sesudah Pemberian Penyuluhan Melalui Metode Ceramah dan Diskusi

\begin{tabular}{lcccc}
\hline \multirow{2}{*}{ Pengetahuan } & \multicolumn{2}{c}{ Sebelum } & \multicolumn{2}{c}{ Sesudah } \\
\cline { 2 - 5 } & n & \% & n & \% \\
\hline Baik & 8 & 17,8 & 38 & 84,4 \\
\hline Cukup & 10 & 22,2 & 7 & 15,6 \\
\hline Kurang & 27 & 60,0 & - & - \\
\hline Total & 45 & 100 & 45 & 100 \\
\hline
\end{tabular}

Sumber: Data Primer, 2017 
Berdasarkan tabel 4 dapat diketahui bahwa sebagian besar pengetahuan peserta kegiatan pengabdian masyarakat sebelum diberikan penyuluhan kurang yaitu sebesar $60 \%$, setelah diberikan penyuluhan hampir seluruh peserta kegiatan pengabdian masyarakat memiliki pengetahuan yang baik yaitu sebanyak $84,4 \%$.

Pendidikan kesehatan merupakan upaya untuk mempengaruhi dan mengajak orang lain baik individu, kelompok, atau masyarakat agar melaksanakan perilaku hidup sehat. Pendidikan kesehatan bisa dilaksanakan dengan berbagai macam hal antara lain penyuluhan, dan pemberian pelatihan. Diharapkan melalui pendidikan kesehatan dapat mengubah perilaku masyarakat dari perilaku yang negatif mengarah ke perilaku yang positif. Untuk mencapai perilaku positif terdapat beberapa faktor yang mempengaruhi proses perubahan tersebut, sesuai dengan teori Green (1980 dalam Notoatmodjo, 2003) yaitu predisposing factors, enabling factors, dan reinforcing factors. Selain itu sesuai dengan teori Rogers (1995 dalam Notoatmodjo, 2007), proses perubahan perilaku juga didahului oleh perubahan pengetahuan, perubahan sikap atau persuasi, pengambilan keputusan, sehingga pada akhirnya akan tercapai tahap implementasi dan konfirmasi.

Dalam pelaksanaan kegiatan pengabdian masyarakat ini materi disampaikan oleh dosen dan mahasiswa. Materi yang disampaikan antara lain tentang anatomi payudara dan fisiologi menyusui (mekanisme produksi ASI dan cara kerja menyusui), keuntungan menyusui, manfaat ASI, dampak dan bahaya susu formula-dot, risiko tidak memberikan ASI - tidak menyusui dan perawatan payudara selama hamil, IMD, pentingnya rawat gabung dan bedding in, demonstrasi cara memosisikan bayi, informasi mengenai perkembangan berat badan bayi ASI eksklusif, masalah atau kendala yang timbul pada proses menyusui dan manajemen ASI perah pada ibu bekerja.

Materi pelatihan disampaikan dengan berbagai macam metode. Selain menggunakan metode ceramah, pemberian materi juga menggunakan metode demonstrasi. Metode demonstrasi yaitu memperlihatkan dan memperagakan sesuatu secara nyata yang disertai dengan penjelasan verbal.
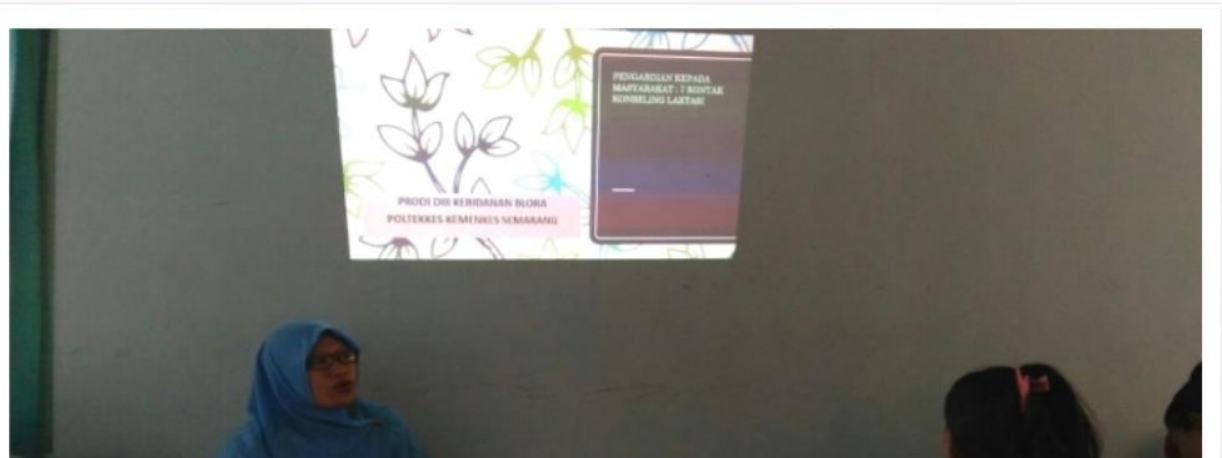


\section{Gambar 1. Pemberian Penyuluhan dengan Metode Ceramah}

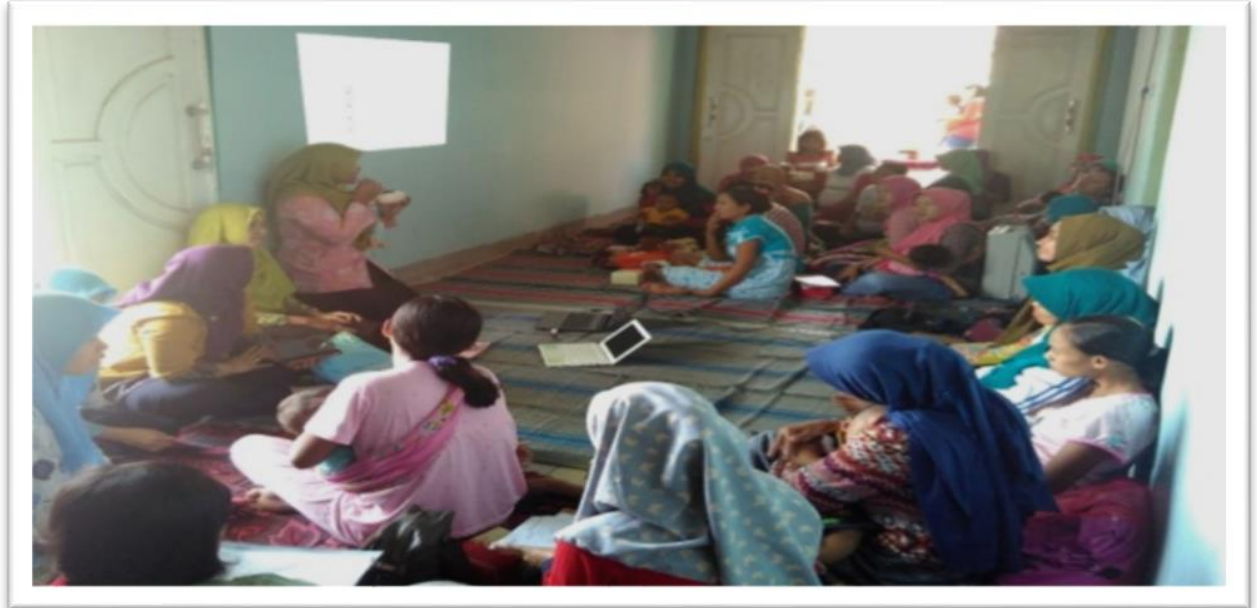

Gambar 2. Pemberian Penyuluhan dengan Metode Demonstrasi

Dari hasil analisis data tentang kegiatan pengabdian masyarakat didapatkan bahwa pengetahuan peserta pengabdian masyarakat mengalami peningkatan setelah mendapatkan penyuluhan menggunakan metode ceramah dan demonstrasi. Hal tersebut menunjukkan adanya pengaruh yang signifikan berupa peningkatan pengetahuan peserta pengabdian masyarakat. Sebelum diberikan penyuluhan dengan metode ceramah dan demonstrasi sebagian besar peserta berpengetahuan kurang (60\%), setelah dilakukan intervensi dalam bentuk ceramah dan demonstrasi terjadi peningkatan pengetahuan. Hampir seluruh peserta pengabdian masyarakat berpengetahuan baik $(84,4 \%)$.

Hal ini sejalan dengan penelitian Hidayati, Salawati dan Istiana (2015) yang menyatakan bahwa metode demonstrasi lebih mudah untuk menunjukkan pengertian, ide, dan prosedur tentang suatu hal yang pernah dipersiapkan dengan teliti untuk memperlihatkan bagaimana cara melaksanakan suatu tindakan adegan dengan menggunakan alat peraga. Hal ini berarti metode demonstrasi bisa berguna untuk meningkatkan pengetahuan. Penyuluhan menggunakan demonstrasi menjadikan proses 
penerimaan sasaran terhadap materi penyuluhan lebih berkesan secara mendalam sehingga membentuk pengertian dengan baik dan sempurna.

\section{SIMPULAN DAN SARAN}

Berdasarkan tujuan awal kegiatan pengabdian masyarakat yang telah ditetapkan dan hasil yang telah diketahui, maka kesimpulan dari pengabdian masyarakat ini adalah ada peningkatan pengetahuan ibu hamil tentang manfaat tujuh kontak konseling laktasi yang bisa mengurangi risiko terjadinya postpartum blues.

Saran yang diberikan setelah dilaksanakannya kegiatan pengabdian kepada masyarakat ini adalah bagi institusi pendidikan agar kegiatan serupa bisa dilaksanakan secara kontinue sehingga bisa memberikan kontribusi langsung kepada masyarakat dalam upaya meningkatkan derajat kesehatan, dan bagi masyarakat yaitu bisa menerapkan tujuh kontak konseling laktasi untuk mengurangi risiko terjadinya postpartum blues.

\section{UCAPAN TERIMAKASIH}

Terima kasih kami sampaikan kepada Poltekkes Kemenkes Semarang yang telah mendanai keberlangsungan kegiatan pengabdian kepada masyarakat ini, Direktur Poltekkes Kemenkes Semarang, Ketua Jurusan Kebidanan Poltekkes Kemenkes Semarang, Ketua Program Studi D III Kebidanan Blora, seluruh dosen, karyawan, mahasiswa, dan Bidan pembantu lapangan, serta Masyarakat yang telah membantu terselesaikannya kegiatan pengabdian kepada masyarakat "Tujuh Kontak Konseling Menyusui sebagai Upaya Mencegah Terjadinya Postpartumblues”.

\section{DAFTAR PUSTAKA}

Azwar, S. 1995. Sikap Manusia Teori dan Pengukurannya. Yogyakarta: Pustaka Pelajar.

Bobak. 2000. Maternity and gynecology care. 5. ed. Philadelphia: Mosby.

Hurlock, B. Elizabeth. 1980. Psikologi Perkembangan Suatu Pendekatan Sepanjang Rentang Kehidupan (edisi kelima). Jakarta: Erlangga.

Masoara, S. 2003. Manfaat ASI untuk bayi, ibu dan keluarga - Program Manajemen Laktasi. Jakarta: Perkumpulan Perinatologi Indonesia. 
Notoadmodjo, S. 2007. Promosi Kesehatan dan Ilmu Perilaku. Jakarta: Rineka Cipta.

Proverawati, A., dkk. 2010. Kapita Selekta ASI \& Menyusui. Yogyakarta: Nuha Medika.

Kemenkes RI. 2013. Riset Kesehatan Dasar. Jakarta: Balitbang Kemenkes RI.

Amir,L.H., Dennerstein, L., Garland, S.M., Fisher, J., \& Farish, S.J. (1996). Psychological aspects of nipple pain in lactating women. Journal of PsychosomaticObstetrics \& Gynecology, 17, 53-58.

Beck, C.T. 2006. Postpartum Depression: It Isn’t Just The Blues. American Journal.

Bobak, Laudermilk, Jensen. 2005. Buku Ajar Keperawatan Maternitas. Jakarta: EGC.

Bogen DL, Hanusa BH, Moses-Kolko E, Wisner KL. 2010. Are maternal depression or symptom severity associated with breastfeeding intention or outcomes. Pubmed. Vol no 8 hal 71-78.

Budihastuti, S. F., Hakimi, M., Sunartini, Soejono, S. K. (2012). Konseling dan Mekanisme Koping Ibu Bersalin. Journal of Educational, Health and CommunityPsychologi 2012 Vol.1 No.1.

Dias CC dan Figueiredo B. (2015). Breastfeeding and depression: a systematic review of the literature. Pubmed. Vol no hal 142-154.

Fiona Marshall, 2004. Mengatasi Depresi pasca melahirkan. Jakarta: Arcan.

Groër, M.W., Davis, M.W., \& Hemphill, J. (2002). Postpartum stress: Current concepts and the possible protective role of breastfeeding. Journal of Obstetric, Gynelogic, \& Neonatal Nursing, 31, 411-417.

Henshaw, C., Foreman, D., \&Cox, J. (2003). Postnatal Blues: a Risk Factor forPostnatal Depression. Journal of Psychosomatic Obstetrics and Gynaecology;25(3-4):26772.

Indarti, J. 2004. Panduan Kesehatan Wanita. Jakarta: Puspa Swara.

Kendall-Tackett, K.A. (2007). A new paradigm for depression in new mothers: The central role of inflammation and how breastfeeding and anti-inflammatory treatments protect maternal mental health. International Breastfeeding Journal.

Kenwa,P., Karkata, M.K., Triyani, IGA. (2015). Pengaruh Pemberian Konseling Terhadap Depresi Post Partum Di Puskesmas II Dan IV Denpasar Selatan. Coping Ners Journal. Vol 3 No 2.

Masmoudi J, Charfeddine F, Trabelsi S, Feki I, Ben Ayad B, Guermazi M, Baâti I, Jaoua A. Postpartum depression: prevalence and risk factors. A prospective Study concerning 302 Tunisian parturients. Tunis Med.2014;92(10):615-21. 
Mezzacappa, E.S., \& Katkin, E.S. 2002. Breastfeeding is associated with reduced perceived stress and negative mood in mothers. Health Psychology, 21, 187-193.

Masruroh. (2013). Hubungan Antara Paritas Ibu Dengan Kejadian Postpartum Blues. Jurnal Eduhealth Vol 3 no 2 Hal 120-125.

Orshan, S. A. 2008. Maternity, Newborn, and Women's Health Nursing. Philadelphia: Lippincott William\&Wilkins Inc.

WHO. 2014. Pelatihan Konseling Menyusui Modul 40 Jam (standar WHO/KEMKES/UNICEF). Jakarta : Perinasia.

Wijayanti K, Wijayanti, F.A., Nuryanti, E. 2013. Gambaran Faktor-Faktor Risiko Postpartum blues di Wilayah Kerja Puskesmas Blora. Poltekkes Kemenkes Semarang.

Zubaran C dan Foresti K. 2013. The correlation between breastfeeding self-efficacy and maternal postpartum depression in southern Brazil. Pubmed. Vol 4 no 1 hal 9-15. 